\title{
Evaluation of Methods for Transient Transfection of a Murine Macrophage Cell Line, RAW 264.7
}

BioTechniques 27:824-832 (October 1999)

\author{
C.D. Thompson, M.R. \\ Frazier-Jessen, R. Rawat, \\ R.P. Nordan and R.T. Brown ${ }^{1}$ \\ OTRR/CBER/FDA, Bethesda, \\ ${ }^{1}$ University Of Maryland, \\ College Park, MD, USA
}

\begin{abstract}
Monocyte/macrophage cell lines are fastidious cells commonly used in transient transfection experiments. In the course of a study of gene regulation by lipopolysaccharide (LPS), we have compared several methods for DNA-mediated cell transfection to determine which would be optimally applicable to the macrophage line, RAW 264.7. Both the response level (LPS inducibility) and the degree of inter-assay variation were evaluated for each transfection technique. The following methods were compared: LIPOFECTIN $^{\circledR}$, LIPOFECTAMINE ${ }^{T M}$, LIPOFECTAMINE PLUS ${ }^{T M}$, SuperFect ${ }^{T M}, \mathrm{Ca}_{3}\left(\mathrm{PO}_{4}\right)_{2}$ DNA co-precipitation, DEAE dextran-mediated transfection and electroporation. The transfected plasmid DNA included a luciferase reporter construct containing the junB minimal promoter under the control of an LPS-inducible 1300-bp regulatory fragment downstream of junB 5'-flanking sequence, as well as a $\beta$-galactosidase reporter construct under the adenovirus promoter and enhancer used as an internal control. Electroporation, followed by a rest-
\end{abstract}

ing period of 16-24 $h$ before stimulation with LPS, had the highest inducibility of all methods. DEAE dextran and $\mathrm{Ca}_{3}\left(\mathrm{PO}_{4}\right)_{2}$ precipitation showed the least and the greatest inter-assay variation, respectively. For all other methods, inter-assay variability fell within this range. The results presented may serve as both a general reference and $a$ guide for reporter gene studies in this or other macrophage cell lines.

\section{INTRODUCTION}

Endotoxin (lipopolysaccharide [LPS]), a constituent of the outer membrane of the cell wall of gram-negative bacteria, stimulates macrophages to produce and release endogenous mediators by means of the coordinated activation of a gene cascade. The inflammatory properties of LPS may contribute to catastrophic responses in humans, such as those occurring during sepsis. LPS possesses pleiotropic activities and affects cells of different lineages. Macrophages, however, play a central role in the inflammatory response to LPS, and it is therefore of interest to study the effect of LPS on gene activation in these cells. The RAW 264.7 cell line has been used as a model for studying LPS gene effects in macrophages (4).

The immediate early gene, $j u n B$, is activated by LPS in the mouse macrophage-like cell line, J774 (2) and in the RAW 264.7 murine cell line (FrazierJessen, unpublished data). Thus, junB reporter constructs can be used to define the elements responsible for the activation of junB by LPS in RAW 264.7 cells. An adequate characterization of gene activation involves optimization of transfection protocols for maximal signal-to-background ratio and low interassay variability. Various transfection methods were used to identify a technique that satisfied these criteria. Here, we report a characterization of these methods with respect to response differential and assay robustness.

\section{MATERIALS AND METHODS}

\section{Reagents}

LPS from Escherichia coli (serotype 0111:B4) and chloroquine were purchased from Sigma (St. Louis, MO, USA) and dissolved in phosphatebuffered saline (PBS). Products purchased from Life Technologies (Gaithersburg, MD, USA) included LIPOFECTIN $^{\circledR}$, LIPOFECTAMINE ${ }^{\mathrm{TM}}$, LIPOFECTAMINE PLUS ${ }^{\mathrm{TM}}$, Calcium Phosphate Transfection System and OptI-MEM $^{\circledR}$. SuperFect ${ }^{\mathrm{TM}}$ Transfection Reagent was obtained from Qiagen (Valencia, CA, USA) and DEAE dextran (average mol wt 500 000) was purchased from Amersham Pharmacia Biotech (Piscataway, NJ, USA).

\section{Cell Culture}

The murine macrophage cell line 
RAW 264.7 was cultured in RPMI 1640 medium supplemented with 2 mM L-glutamine (BioWhittaker, Walkersville, MD, USA), $100 \mu \mathrm{g} / \mathrm{mL}$ gentamicin (Life Technologies) and 10\% fetal bovine serum (R10; BioWhittaker). Cells were maintained in a humidified atmosphere of $5 \% \mathrm{CO}_{2}$ at $37^{\circ} \mathrm{C}$.

\section{Plasmids}

The construction of plasmids used in this study has been previously described (1). The plasmid construct, pGL2JP/1.5-2.8DR, contains the murine junB promoter and a 1300-bp region of DNA that lies downstream of the jun $B$ coding region. The carrier plasmid used in the electroporation transfections was pGL2.NOT1, encompassing the pGL2Basic vector (Promega, Madison, WI, USA) with an additional Not1 cloning site added as an intermediate step in the construction of the junB reporter gene vectors. All transient expression experiments included co-transfection with pAD $\beta$ plasmid, a vector in which expression of $\beta$-galactosidase ( $\beta$-gal) is regulated by the adenovirus major late promoter (CLONTECH Laboratories, Palo Alto, CA, USA). All plasmids used for transfection were purified twice on cesium chloride-ethidium bromide gradients (3).

\section{Calcium Phosphate Transfection}

Calcium phosphate transfections were performed by the method of Smith et al (4). Briefly, for each transfection, a set of four wells containing 5 $\times 10^{5}$ cells was distributed in 24-well plates in $1.0 \mathrm{~mL}$ of R10 and incubated for $16-24 \mathrm{~h}$ in $5 \% \mathrm{CO}_{2}$ at $37^{\circ} \mathrm{C}$. Calcium phosphate/DNA precipitates were made in 1-mL volumes with $3.0 \mathrm{pmol}$ of pGL2JP/1.5-2.8DR and $3.0 \mathrm{pmol}$ of $\mathrm{pAD} \beta$, according to the manufacturer's instructions. The medium was aspirated from the wells containing the cells. Each calcium phosphate/DNA precipitate was divided into four of the wells, followed by an incubation at room temperature for $20 \mathrm{~min}$. Two milliliters of R10 were added to each well, and plates were incubated in $5 \% \mathrm{CO}_{2}$ at $37^{\circ} \mathrm{C}$ for $2 \mathrm{~h}$. Chloroquine was added to each well to a final concentration of
$100 \mu \mathrm{M}$, and the incubation was continued for an additional $3 \mathrm{~h}$. Medium was aspirated from the wells, and the cells were carefully washed in $1.0 \mathrm{~mL}$ of PBS. Wells were replenished with 2 $\mathrm{mL}$ of R10 and incubated in $5 \% \mathrm{CO}_{2}$ at $37^{\circ} \mathrm{C}$ for a total of $24 \mathrm{~h}$ from the start of transfection.

\section{DEAE Dextran Transfection}

For transfection with DEAE dextran, the cells were seeded $16-24 \mathrm{~h}$ before transfection in 6-well plates at a density of $1 \times 10^{6}$ cells in $2.0 \mathrm{~mL}$ of R10. For each transfection, 2 pmol of pGL2JP/1.5-2.8DR and 2 pmol of pAD $\beta$ were diluted into $600 \mu \mathrm{L}$ of PBS containing $20 \mu \mathrm{L}$ of $10 \mathrm{mg} / \mathrm{mL}$ DEAE dextran (322 $\mu \mathrm{g} / \mathrm{mL}$ final). Cells were washed once in PBS, then incubated with DEAE dextran/DNA for $30 \mathrm{~min}$ in $5 \% \mathrm{CO}_{2}$ at $37^{\circ} \mathrm{C}$. Two $\mathrm{mL}$ of RPMI containing $100 \mu \mathrm{M}$ chloroquine (without serum) were added to each well, followed by incubation for $90 \mathrm{~min}$ in $5 \% \mathrm{CO}_{2}$ at $37^{\circ} \mathrm{C}$. Cells were washed once in PBS and cultured in R10 for a total of $24 \mathrm{~h}$ from the start of transfection.

\section{LiPOFECTIN Transfection}

For each transfection with LIPOFECTIN, $1 \times 10^{6}$ cells were distributed in 6-well plates with $2.0 \mathrm{~mL}$ of R10 without antibiotics and incubated for 16-24 $\mathrm{h}$ in $5 \% \mathrm{CO}_{2}$ at $37^{\circ} \mathrm{C}$. Transfections were performed according to the manufacturer's instructions with $6 \mu \mathrm{L}$ LIPOFECTIN and 1 pmol each of pGL2JP/1.52.8DR and pAD $\beta$ plasmids. Samples were incubated for $5 \mathrm{~h}$ in $5 \% \mathrm{CO}_{2}$ at $37^{\circ} \mathrm{C}$ before the addition of $1.0 \mathrm{~mL}$ of RPMI $1640 / 20 \%$ fetal calf serum (FCS), then incubated again at $37^{\circ} \mathrm{C}$ for a total of $24 \mathrm{~h}$ from the start of transfection.

\section{LIPOFECTAMINE and LIPOFECT- AMINE PLUS Transfections}

Cells were incubated in 6-well plates as in the LiPOFECTIN transfections. Transfection reagents-6 $\mu \mathrm{L}$ LIPOFECTAMINE reagent or $4 \mu \mathrm{L}$ LIPOFECTAMINE and $6 \mu \mathrm{L}$ of PLUS reagent diluted in OpTI-MEM medium-were used according to the manufacturer's instructions. Every transfection included 0.25 pmol each of pGL2JP/1.5$2.8 \mathrm{DR}$ and $\mathrm{pAD} \beta$ plasmid and was treated as in LIPOFECTIN transfections.

\section{SuperFect Transfection}

For each transfection, $1 \times 10^{6}$ cells were distributed in wells of 6-well plates in $2 \mathrm{~mL}$ of R10 without antibiotics and incubated for $16-24 \mathrm{~h}$ in 5\% $\mathrm{CO}_{2}$ at $37^{\circ} \mathrm{C}$. Transfections were performed according to the manufacturer's instructions using $5 \mu \mathrm{L}$ of SuperFect reagent and 0.25 pmol each of pGL2JP/1.5-2.8DR and pAD $\beta$ plasmids. Reagent/DNA was incubated with the cells for $2 \mathrm{~h}$ at $37^{\circ} \mathrm{C}$, then washed 3 times in $2 \mathrm{~mL}$ of PBS. Wells were replenished with $2 \mathrm{~mL}$ of R10 and incubated at $37^{\circ} \mathrm{C}$ for a total of $24 \mathrm{~h}$ from the start of transfection.

\section{Electroporation}

Cells were pelleted and resuspended to $2 \times 10^{7}$ cells $/ \mathrm{mL}$ in R10. Then, 250 $\mu \mathrm{L}$ of cell suspension $\left(5 \times 10^{6}\right.$ cells $)$ were electroporated at room temperature with $1.0 \mathrm{pmol}$ of pGL2JP/1.52.8DR plasmid, 1.0 pmol of $\mathrm{pAD} \beta$ plasmid and 3.0 pmol of carrier plasmid per transfection. Electroporation was performed with a CELL-PORATOR ${ }^{\circledR}$ (Life Technologies) at $200 \mathrm{~V}$ and 1600 $\mu \mathrm{F}$ on low-resistance setting. Electroporated cells were incubated in $10 \mathrm{~mL}$ of R10 in $15-\mathrm{mL}$ tubes in $5 \% \mathrm{CO}_{2}$ at $37^{\circ} \mathrm{C}$ for the indicated times.

\section{Stimulation of Transfected Cells With LPS}

After the specified incubation period, all transfected cells were stimulated for $4 \mathrm{~h}$ with $1 \mu \mathrm{g} / \mathrm{mL}$ LPS before harvesting.

\section{Assay of Luciferase and $\beta$-Gal}

Electroporated cells were pelleted, washed with PBS and lysed for 15 min at room temperature in $50 \mu \mathrm{L}$ of reporter lysis buffer (Promega). LiPoFECTIN, LIPOFECTAMINE, LIPOFECTAMINE PLUS, calcium phosphate, SuperFect and DEAE-dextran transfected cells were washed once with PBS in 
the plates, lysed for $15 \mathrm{~min}$ in $100 \mu \mathrm{L}$ of reporter lysis buffer and harvested by scraping cells from the wells. Luciferase and $\beta$-gal were then assayed as previously reported (1). For all cell lysates, reporter gene luciferase activity was normalized by dividing the $\beta$-gal value from the same lysate (normalized luciferase value).

\section{RESULTS}

To minimize interference by undesired contaminants, all reporter plasmids used in this study were purified by two rounds of CsCl-gradient centrifugation. DNA prepared by the CsClgradient method has also been reported to yield the highest transfection efficiencies (5). Several luciferase plasmid constructs (1) of various regions of the junB promoter/enhancer and a construct containing the full-length gene were tested for inducibility in RAW 264.7 cells in preliminary screening experiments (data not shown).

From the results of these experiments, pGL2JP/1.5-2.8DR was selected because it gave the greatest amount of inducibility based on the calcium phosphate protocol. Using this luciferase reporter plasmid, we tested various transfection methods, including LiPOFECTIN, LiPOFECTAMINE, LiPOFECTAMINE PLUS, SuperFect, $\mathrm{Ca}_{3}$ $\left(\mathrm{PO}_{4}\right)_{2}$ DNA co-precipitation, DEAE dextran-mediated transfection and electroporation. We found that RAW 264.7 cells could be transiently transfected with all methods used. All techniques were independently optimized in this cell line for the amount of DNA, amount of transfection reagent, cell number and length of exposure of cells to the transfection reagents.

The optimal time for assaying transcription following transfection was determined based on known qualities of each procedure and on experimental data. When transfecting by electroporation, plasmid DNA is introduced into cells through pores in the cell membrane formed by the electrical current. Approximately 15\% of the RAW 264.7 cells survive after being electroporated (data not shown), although the plasmid DNA expression is rapid compared to that of the other reagent-mediated
Table 1. Inter-Assay Variation of Transfection Methods as Determined by Coefficients of Variation for Uncorrected and Normalized Luciferase Activity

\begin{tabular}{|lcc|}
\hline Method & $\begin{array}{c}\text { Uncorrected } \\
\text { Luciferase Value }\end{array}$ & $\begin{array}{c}\text { Normalized } \\
\text { Luciferase Value }\end{array}$ \\
DEAE Dextran (5) & 30.4 & 30.3 \\
LIPOFECTIN (5) & 54.2 & 49.8 \\
Electroporation 24 h (4) & 84.0 & 56.0 \\
LIPOFECTAMINE PLUS (5) & 126.6 & 72.3 \\
LIPOFECTAMINE (5) & 124.5 & 77.3 \\
SuperFect (5) & 46.1 & 89.4 \\
Calcium Phosphate (7) & 137.3 & 96.9 \\
The number of transfection experiments performed for each technique is written \\
in parentheses next to the technique.
\end{tabular}

transfection techniques. In contrast, LIPOFECTIN, LIPOFECTAMINE, LIPOFECTAMINE PLUS, calcium phosphate, SuperFect, and DEAE dextran are chemical-based transfection methods, in which the uptake of plasmid DNA is either by charge interaction with and transfer through the mem-

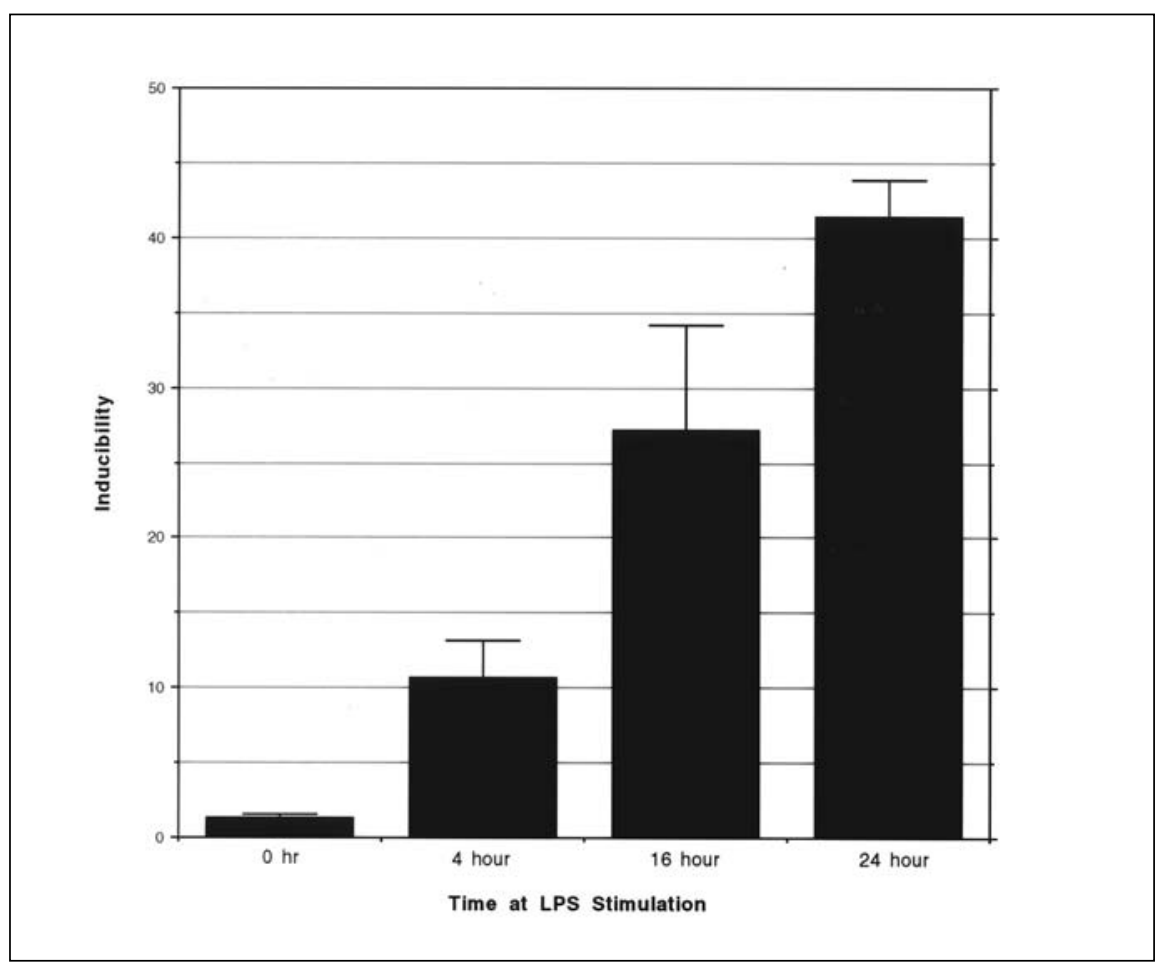

Figure 1. Time dependency of LPS inducibility of the junB-promoter/enhancer, conferred by LPS on electroporated RAW 264.7 cells. Cells were electroporated with pGL2JP/1.5-2.8DR luciferase reporter, pAD $\beta$, $\beta$-gal reporter and the carrier, pGL2.NOT1. The electroporated cells were then incubated for $0,4,16$ or $24 \mathrm{~h}$ before the addition of $1 \mu \mathrm{g} / \mathrm{mL}$ LPS for $4 \mathrm{~h}$. (Error bars indicate standard errors of the mean.) 
A

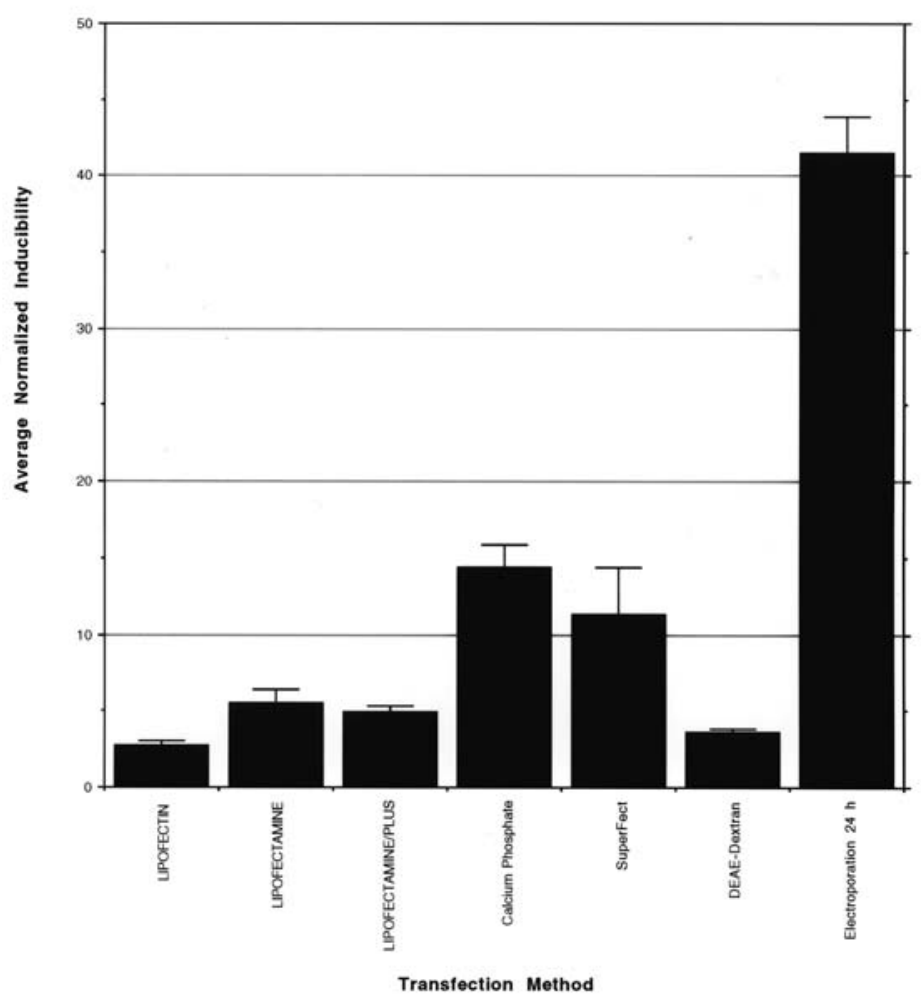

B

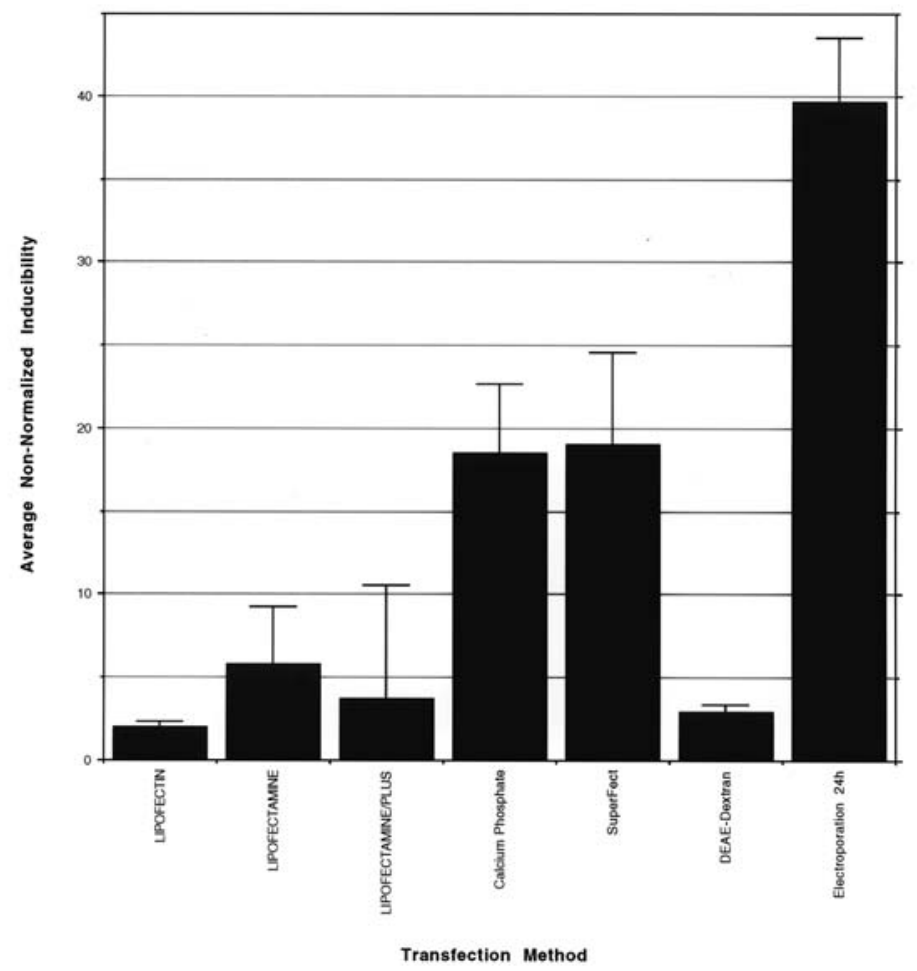

Figure 2. Comparison of average inducibilities of the junB promoter/enhancer, conferred by LPS, on RAW 264.7 cells using various transfection methods. RAW 264.7 cells were transfected using various techniques as described in Materials and Methods and stimulated with $1 \mu \mathrm{g} / \mathrm{mL}$ LPS for $4 \mathrm{~h}$. (A) Average of $\beta$-gal-normalized inducibility values and (B) average non-normalized inducibility values for the various methods tested. At least four individual experiments were performed for each method. (Error bars indicate standard errors of the mean.) brane or by DNA precipitation and phagocytosis of the precipitated complexes. These reagent-mediated methods are relatively gentle and cause less cell death when compared to electroporation, but entry of the plasmid DNA into the cell and its subsequent expression takes longer. A 24-72-h interval is usually recommended to allow for optimal expression of the plasmid DNA after reagent-mediated transfection. Based on the supplier's recommendation, an experiment was performed using LipofeCtin, LipofECTAMINE and LIPOFECTAMINE PLUS to determine the point at which luciferase and $\beta$-gal expression were the greatest. RAW 264.7 cells were transfected with pGL2JP/1.5-2.8DR and pAD $\beta$ plasmids, and samples were harvested at 24, 31, 48, 55 and 72 h. Reporter plasmid gene expression was found to be the highest at $24 \mathrm{~h}$ and decreased at later time points (data not shown).

We next explored the effect of recovery time on transfection performance. In our calcium phosphate, SuperFect and DEAE dextran transfections, the reagents were washed away from the cells after 5,2 or $2 \mathrm{~h}$ of incubation, respectively. For LiPOFECTIN, LIPOFECTAMINE and LIPOFECTAMINE PLUS, the reagents were left on the cells for the entire incubation time, but at one-half the starting concentration. We assessed the degree to which a recovery time for the cells exposed to these reagents affects transfection performance. LIPOFECTAMINE PLUS, which has a mode of action similar to some of the other reagentbased methods, was selected. RAW 264.7 cells were transfected, with pGL2JP/1.5-2.8DR and pAD $\beta$ plasmids, and one-half of the transfected samples were incubated with medium alone or in the presence of LPS (1 $\mu \mathrm{g} / \mathrm{mL}$ ) for $4 \mathrm{~h}$ starting at times $0,4,24$ or $48 \mathrm{~h}$ after transfection. The LPS inducibility, calculated after $\beta$-gal normalization, was 3.3, 9.1, 5.9 and 6.0, respectively (data not shown). Thus, recovery time does not appear to affect performance in cells transfected by LiPOFECTAMINE PLUS. Note that the other reagent-based methods have even less exposure to potentially toxic chemicals than the LipOFECTAMINE PLUS method. Hence, it is unlikely 
that recovery time has any impact on performance of reagent-mediated transfections. Therefore, a 24-h time interval after the start of transfection was chosen as a standard time to initiate LPS stimulation for comparison of all reagent-mediated transfection techniques.

In the case of electroporation, the effect of recovery time after transfection on junB inducibility by LPS was studied in detail because the method damages the cells at the same time it promotes DNA transfection. RAW 264.7 cells were transfected by electroporation and then induced with LPS after various time intervals. Inducibility of the jun $B$ construct in these cells was determined by incubating one-half of the transfected samples with medium alone or in the presence of LPS $(1 \mu \mathrm{g} / \mathrm{mL})$. Little inducibility was observed when LPS stimulation was performed immediately after electroporation (Figure 1). A substantial increase in inducibility (to 41.5), however, was observed by increasing the resting time up to $24 \mathrm{~h}$ between transfection and LPS treatment. In addition, the luciferase activity waned at time points greater than $24 \mathrm{~h}$ because of the degradation of the luciferase signal (data not shown). Thus, $24 \mathrm{~h}$ was the optimal delay for detection of activity in these cells after electroporation.

A comparison of junB inducibility by LPS in RAW 264.7 cells for all transfection methods is shown in Figure 2A. LPS inducibility in cells transfected by all reagent-mediated methods was less than that seen in electroporated cells, with calcium phosphate being the second best at 14.4. The lowest inducibility of 2.76 was obtained using LIPOFECTIN, although all techniques resulted in some LPS inducibility. LPS inducibility was also calculated for each transfection method with or without $\beta$-gal normalization (Figure 2, A and $B$ ). The overall pattern of inducibility was similar for normalized and non-normalized (uncorrected) data. Because normalization corrects for differences in transfection efficiency between samples, as well as for the potential differences in the number of cells harvested, the normalized values represent a more reliable estimate of inducibility.
Variation of reporter gene activity from transfection to transfection is a measure of a method's robustness. To assess this, we performed four or more independent experiments with each method and calculated the coefficient of variation (cv). DEAE dextran showed the lowest cv for both uncorrected and $\beta$-gal-normalized luciferase expression (Table 1). The calcium phosphate technique showed the highest cv for both uncorrected and normalized luciferase expression.

\section{DISCUSSION}

Among the eukaryotic cell transfection methods examined, electroporation showed the greatest inducibility of a junB reporter gene in RAW 264.7 cells (41.5 vs. 14.4 for calcium phosphate, the second best). On the other hand, inducibility for DEAE dextran transfection was comparably low, but showed the lowest cv (30.3 vs. 56.02 for electroporation) calculated for $\beta$ gal-normalized luciferase activity.

The cv for the $\beta$-gal-normalized luciferase values ranged from 30.3 for DEAE dextran to 96.9 for the calcium phosphate method. The $\mathrm{cv}$ for the $\beta$ gal-normalized luciferase activity was lower than the uncorrected luciferase activity in all cases except for the SuperFect method, which indicated that normally the two parameters are correlated. $\beta$-gal normalization is therefore effective for compensating for inter-assay variation ascribable to transfection efficiencies. The discrepancy observed with the SuperFect method suggests that normalization by $\beta$-gal co-transfection by this method may not be appropriate. This may be due to dis-homogeneous insertion of plasmid DNA by this method, resulting in only partial overlapping populations of cells transfected with both plasmids.

In conclusion, of the different transient transfection techniques evaluated, electroporation is superior overall when a larger induction window is desired. If experiment-to-experiment variation is the greatest concern, DEAE dextran transfection should be considered. These results may serve as a general guide to other investigators with an interest in performing reporter gene studies in RAW 264.7 cells or similar cells.

\section{ACKNOWLEDGMENTS}

This article is dedicated to the memory of Dr. Richard P. Nordan, who passed away during preparation of the manuscript. We would like to thank Drs. Ezio Bonvini and Kurt Brorson for their discussion and critical review of this manuscript.

\section{REFERENCES}

1.Brown, R., I. Ades and R. Nordan. 1995. An acute phase response factor/NFkB site downstream of the junB gene that mediated responsiveness to interleukin-6 in a murine plasmacytoma. J. Biol. Chem. 270:31129-31135.

2.Fujihara, M., M. Muroi, Y. Muroi, N. Ito and T. Suzuki. 1993. Mechanism of lipopolysaccharide-triggered junB activation in a mouse macrophage-like cell line (J774). J. Biol. Chem. 268:14898-14905.

3.Sambrook, J., E.F. Fritsch and T. Maniatis. 1989. Molecular Cloning: A Laboratory Manual, 2nd ed. CSH Laboratory Press, Cold Spring Harbor, NY.

4.Smith, M.F., Jr., D. Eidlen, W.P. Arend and A. Gutierrez-Hartmann. 1994. LPS-induced expression of the human IL-1 receptor antagonist gene is controlled by multiple interacting promoter elements. J. Immunol. 153:35843593.

5.Weber, M., K. Möller, M. Welzeck and J. Schorr. 1995. Effects of lipopolysaccharide on transfection efficiency in eukaryotic cells. BioTechniques 19:930-940.

Received 19 February 1999; accepted 1 July 1999.

Address correspondence to:
Cynthia Thompson
CBER/FDA/HFM-564
1401 Rockville Pike
Rockville, MD 20852-1428, USA
Internet: thompsonc@cber.fda.gov 